\title{
Effect of Investment in Healthcare One Economic Development in Kenya
}

\author{
Jane Njoki Murango, Wabuyabo-Okonga B. M. \\ Department of Finance \& Accounting, KCA University, Nairobi, Kenya \\ Email address: \\ njokimurango@yahoo.com(Jane N.M.), dokonga@kca.ac.ke(Wabuyabo-Okonga B.M.) \\ ${ }^{*}$ Corresponding author
}

\section{To cite this article:}

Jane Njoki Murango, Wabuyabo-Okonga B. M. Effect of Investment in Healthcare One Economic Development in Kenya. Journal of Investment and Management. Vol. 7, No. 1, 2018, pp. 25-34. doi: 10.11648/j.jim.20180701.14

Received: January 9, 2018; Accepted: February 24, 2018; Published: March 2, 2018

\begin{abstract}
Economic development can generally refer to an ikncrease in a country's ability to produce goods and services identified by factors such as production, income and spending. Investment in health in this way becomes a significant variable for economic growth or development since investments in different components of health can lead to improved human capital. Kenya has low investment in the health sector which may adversely affect economic development. The purpose of this study was to explore the effect of investment in health on the economic development in Kenya. The specific objectives were to investigate the effect of public investment in health, private investment and investment in health by international nongovernmental organizations on the development of the economy of Kenya. A descriptive research design was used in this study. Secondary time series data for 32 years (1985-2016) was collected from Kenya National Bureau of Statistics (KNBS), Institute of Economic Affairs (EIA), World Bank, Ministry of Finance and Ministry of Devolution and Planning. Data analysis was conducted using Stata statistical software. VECM time series model was fitted to the data. Augmented Dickey Fuller unit root test and Johansen test of cointegration were conducted to ensure stationarity of the data. The study results suggested that both public investment in health $(\beta=0.1149 ; \mathrm{p}<0.05)$ and private investment in health sector $(\beta=0.2407 ; \mathrm{p}<0.05)$ have significant positive effect on economic development. The study results, however, showed that investment in health sector by INGOs have no significant effect on economic development in Kenya $(\beta=0.3232 ; p>0.05)$. The study makes the following recommendations. First, the government should channel more funding to the health sector as the current funding of $3.4 \%$ of GDP falls below the 7\% set by the Abuja Declaration in 2001. Secondly, private entities should be encouraged to increase their investment in the health sector in the country. Lastly, the ministry of health and other government stakeholders should partner with private health service providers and come up with a framework to ensure that private health sector increases its funding to fill up financial deficit health sector. This is because the research concluded that the private health has significant contribution to the overall performance of the health sector.
\end{abstract}

Keywords: Economic Development, Public Investment in Health, Private Investment in Health

\section{Background of the Study}

The thinking behind the need to take up the research will be provided in the statement of the problem with a brief description of the gaps that the study aims to fill. This will involve providing an insight to the observations made by the author on the current situation between health and the economic development of Kenya that have motivated the research on the topic, and previous works done on the same topic while the objectives will be composed from the variables identified. Since the study is based on commonly used and researched concepts that include economic development and investment in health sector, and being an academic research, the study will be found significant to different individuals identified in the section on significance. This will help emphasize on the importance of the study and the need to invest time and the researcher's resources in order to achieve the expected outcomes.

\subsection{Investment in Health and Economic Development}

Investment in the health sector comprises of the funds 
applied in the different industries in healthcare sector such as pharmaceuticals and devices, hospitals and health insurers to enable the sector to improve its service offering to the population. The traditional concept of health as described by Wang (2013) was based on the assumption that health and disease were objective and observable phenomena. Success in delivery of better health care services from public and private institutions has been seen as a worldwide and global challenge. Health-related goals such as improving the quality of services delivered have been highly regarded globally, nationally and locally for a long time now. Gallup and Sachs (2001) indicate that investments in different components of health can lead to reduced poverty. Kirigia, et al., (2006) point out that poor health delivery affects different components in the socio-economic environment including learning, human capital and the environment for entrepreneurial and productive activities.

Economists such as Hsiao and Heller (2007) and Bloom and Canning (2000) have also recognized that there is a relationship between good health across the whole population and achievement of economic growth. At a societal level, similar investments may lead to demographic changes conducive to economic development. In particular they may lead to a period in which countries have a higher ratio of workers to dependents leading to increased national savings. Economic theory suggests that increased savings ought to enhance growth by providing funding for investment. On the other hand, in the medium term, population growth due to reduced infant mortality could reduce GDP per capita if population growth out passes growth of available resources and capital (Grossman, 2014).

\subsection{Citizen Health Care Facilities in Kenya}

In Kenya, Health services are provided through a network of over 5,000 health facilities countrywide, with the public sector system accounting for about 52; percent of these facilities (Republic of Kenya, 2011). Health services are integrated as one goes down the hierarchy of health structure from the national level to the newly created county levels as envisaged in the 2010 Constitution. County hospitals in this regard concentrate on the delivery of health care services and generate their own expenditure plans and budget requirements based on guidelines from headquarters through the County governments (Republic of Kenya, 2011).

The devolved government, the Kenya Health Policy 20122030 provides guidance to the health sector in terms of identifying and outlining the requisite activities in achieving the government's health goals which have been slowly implemented since the constitution's promulgation (KPMG, 2013). Out of all the health facilities in the country, the MOH controls and runs about $52 \%$ while the private sector, the mission organizations and the Local County Governments run the remaining $48 \%$. The public sector controls about $79 \%$ of the health centers, $92 \%$ of the sub-health centers, and $60 \%$ of the dispensaries. The NGO sector is dominant in health clinics, maternity and nursing homes controlling $94 \%$ of the total while also controlling $86 \%$ of the medical centers in the country (Luoma, 2010).

The under-financing of the health sector has reduced its ability to ensure an adequate level of healthcare for the population. Inefficient utilization of resources, the increasing burden of diseases and the rapid population growth inhibit Kenya's ability to provide adequate healthcare for its citizens (Luoma, 2010). The poor quality health care delivery especially in Kenya has also been attributed to gaps in knowledge and skills compounded by broader system failure and low staff numbers. The need to tackle the gaps in Human Resources for Health (HRH), as an essential part of strengthening health system was emphasized in the 2006 World Health Report (WHO, 2015).

\section{Statement of the Problem}

Good health care contributes to economic performance through higher participation and productivity of the individual employees. This cannot be the case in the face of the various scenes of employee discontentment characterized by strikes and boycotts in the health sector since time immemorial. Their grievances include poor facilities and equipment, poor remuneration, lack of career growth, poor management in the healthcare sector and work overload among other issues (Eneji, Vonke \& Onabe, 2013). Moreover, Kenya failed to attain the Millennium Development Goal 5 of improving maternal health (MDG 5) where key indicators showed deterioration such as neonatal mortality (UNDP, 2016). This scenario could be an indicator that there is a mismatch between the investment in the health sector and the expected outcome of improved health indicators.

Insufficient investment in the health sector has been a problem for long. KIPPRA (2004) explains that Ministry of Health has been struggling to maintain public sector health facilities. This has led to adoption of healthcare policy reforms to supplement government budgets and revitalize healthcare delivery systems. The most notable health reforms the Government has adopted include decentralization and cost sharing. Kenya's investment in the healthcare sector over the past five years (2012-2016) has averaged 2.8\% of the GDP which compares poorly with that of developed countries such as US (10.1\%) and UK (12.5\%), (Piabuo and Tieguhong, 2017). This low investment in the health sector could lead to poor health status of workers thus leading to adverse effects on national productivity and economic development. It is not clear how Kenya's level of investment in health care has contributed to the economic development of the country.

\section{Research Objective}

The main objective of this research was to evaluate the effect of investment in health care sector on the economic development in Kenya. This investment is viewed at three levels; government investment, private sector investment and the international non-governmental organization investment 
in health care affects development of Kenya's economy.

\section{Scope and Significance of the Study}

This study was undertaken in Kenya where findings were based on a desk study that was used to assess the various investments in health on economic development. The study covered the period from 1985 - 2016. The study focused on public investment in health, private investment in health and investment in health by INGOs.

Significance of a study refers to the relevance of the study in terms of academic contributions and practical use that might be made of the findings (Oso \& Onen, 2009). The study will make recommendations on the relationship between investments in health and economic outcomes in Kenya. Undeniably such relations and the recommendations made could inform policy formulations in the various cities and counties in the country in general because they are originated through valid research data. The study findings will relate the different aspects of health measurement with economic development providing professionals in the health and finance ministries to understand their individual contributions to the relationship.

\section{Keynesian Theory}

The Keynesian general theory of employment, interest and money was devised by Keynes (1936). In this theory, Keynes posited that public expenditure causes national income. Keynes rebutted the concept of laissez faire and argued that government expenditure in the various sectors of the economy such as defense, education, health and social security makes economic growth possible. Moreover, he advocated that the increased fiscal activities of the state enabled the economy to grow better than in those jurisdictions that fiscal activities of the state were minimal. The Keynesian theory advocates for government intervention in form of spending, taxation and regulation to stimulate growth in the economy in times of recession as well as depression.

Keynesian approach to fiscal activities in the health sector hypothesizes that investment in the health sector by the government would positively affect economic growth. Labor and capital are indicated as the major drivers of economic growth. When government increases its investment in the health sector, it increases the quality and efficiency of labor by making people healthier and less susceptible to disease. This increases their output and productivity thus enhancing economic growth. Moreover, increased investment in the health sector would lead to increased research and development and thus increasing the health outcomes of the population. A healthy population implies more people available for work and thus productivity is improved (Sammut, 2013).

This theory informed this study by indicating that when governments increase expenditure and investments in the health sector, labor is enhanced and productivity is increased in the economy leading to enhance economic growth. The theory posits that government should commit itself to maintain demand at a high level so that full employment is achieved. The government can do this by recycling the tax revenues it collects by investing it in public infrastructure in the health sector. This would improve the health welfare of the workforce and also increase production among the sectors that serve the health sector.

\section{Research Design and Target Population}

A descriptive research design was used in this study. It was considered a convenient method because it could be completed relatively quickly and it is cost effective. Creswell (2013) defines descriptive research as a fact-finding approach generating across sectional or longitudinal analysis of the situation. This design goes beyond data collection and involves measures, classification, analysis and interpretation (Robson, 2012). The descriptive research in the current study assisted to establish the relationship between health investments and economic growth and hence provide evidence-based findings. The study was based on Kenya. Data that was used in the study was longitudinal data for thirty two years (1985-2016). The 32 years were selected due to the need to use current information on investment in healthcare and also to ensure that the panel is sufficient for inferential analysis. Also, Structural adjustment programs which affected the healthcare sector significantly started in 1985.

\section{Data Collection and Data Analysis}

The study used secondary data from Kenya National Bureau of Statistics (KNBS), Institute of Economic Affairs (EIA), World Bank, Ministry of Finance and Ministry of Devolution and Planning. With the aim of ensuring validity of the information gathered, only authentic sources of data were used which included the government's economic entities, ministries and renowned entities like World Bank. Besides physical access to publications, many online resources entailing array of databases were also utilized for the above-mentioned purpose.

Data analysis was conducted using the Stata statistical software. The data collected was time-series in nature and hence a time-series model was applied in analysis. The time series Vector error correction model (VECM) or the Vector autoregressive (VAR) model were applied depending on the cointegration status of the health investment and economic growth variables. Hacker and Hatemi (2008) posited that VAR model is able to capture the linear interdependencies among the various time series under study. The procedure in VAR enables every variable to take an equation clarifying how it progresses founded on the lags of the other variables and also on its own lags. Hatemi (2004) indicates that VAR modeling only requires a list of variables which are 
hypothesized to influence each other inter-temporally. In this study, the variables included will be public health investment, private health investment, total health investment and economic growth. However, VAR is only suitable when there is no cointegration of the variables. When cointegration exists, VECM is more suitable.

The analysis process in the study entailed three steps. The first step was to load the collected data into the Stata statistical software. The second step was to use the Schwarz's Bayesian information criterion (SBIC) and other lag order selection criteria to establish the appropriate number of lags to use. Lastly, estimation of autoregressive models followed using ordinary least squares method. This estimation enabled fitting of the trend, intercept, and autoregressive integrated moving averages.

\section{Model Specification}

The VAR or VECM model that was applied is a multivariate time series function. The independent variables of the study were public investment in health $(\mathrm{PIH})$, private investment in health $(\mathrm{PrIH})$ and investment in health by INGOs(IINGO). The dependent variable was economic development measured using GDP. The timeseries model was as follows:

$$
\mathrm{GDP}_{\mathrm{t}}=\beta_{0}+\beta_{1} \mathrm{PIH}_{\mathrm{t}}+\beta_{2} \mathrm{PrIH}_{\mathrm{t}}+\beta_{3} \mathrm{IINGO}_{\mathrm{t}}+\varepsilon
$$

Where;

$\beta_{0}$ - Constant showing GDP growth rate in absence of investment in health

PIH- Public investment in health

PrIH- Private Investment in health

T- Time period $(1985-2016)$

IINGOs-- International NGOs investment in health

E-Error term

\section{Research Findings and Discussion}

Data analysis entailed exploratory analysis of the dependent and the independent variables. The exploratory analysis includes the descriptive statistics, growth plots and overlain plots. Figures and tables are used to present the findings and interpretation is provided. A discussion is provided relating the findings to the theoretical and empirical literature.

\subsection{Exploratory Analysis of GDP}

The trend of GDP was explored over the study period from 1985 to 2016 (See Figure 1) established that GDP had an upward trend in the entire study period.

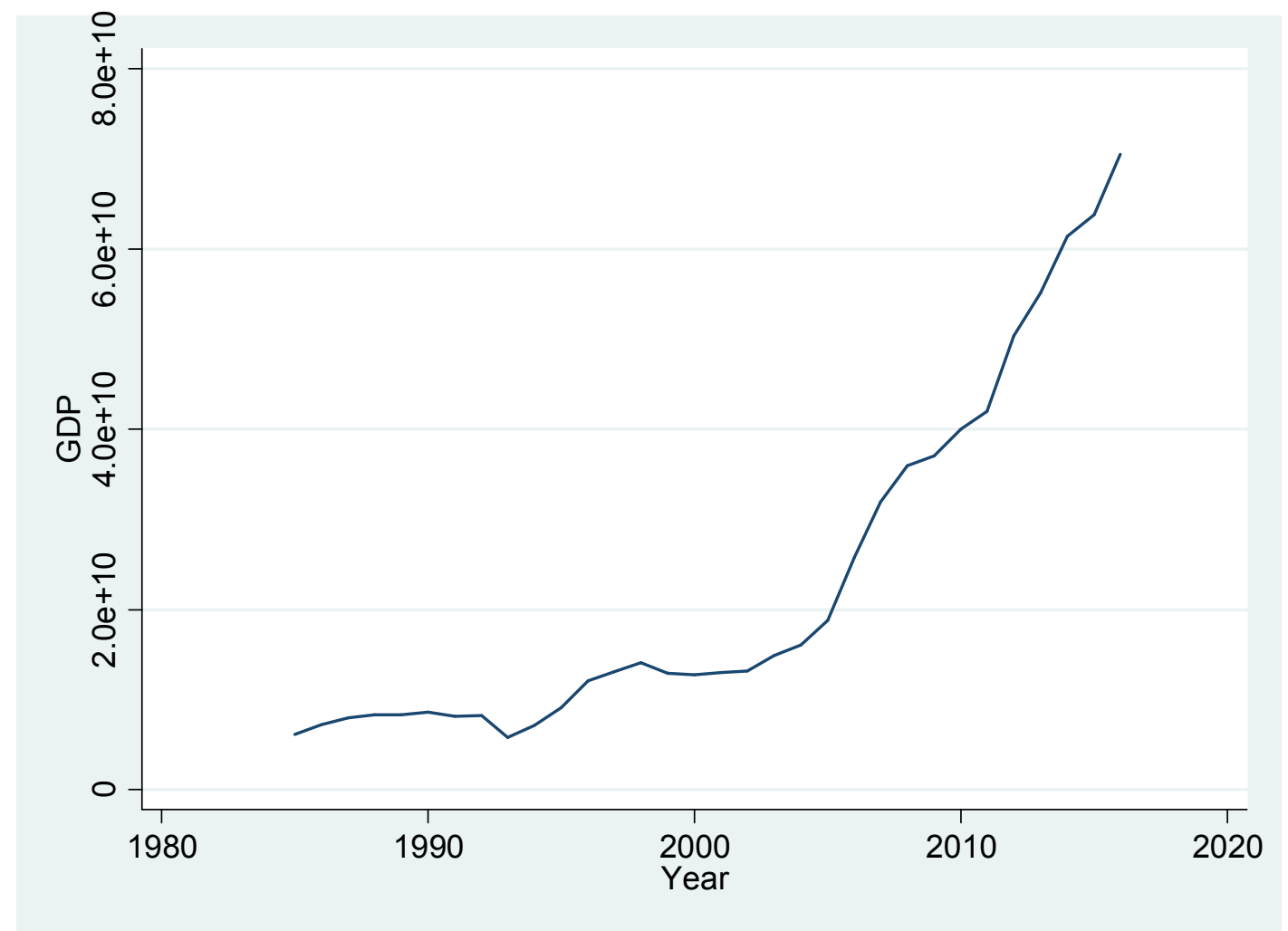

Figure 1. Trend of GDP (USD 1985 - 2016).

Also the trend got steeper from mid 2000s (USD 16 billion) to 2016 (USD 71 billion) indicating increased GDP growth. The only year on year drop in GDP was observed in 1992 where it shrank from USD 8.2 billion to USD 5.8 billion.

\subsection{Growth Plot for Independent Variables}

The study explored how the three independent variables varied over time (See Figure 2). 


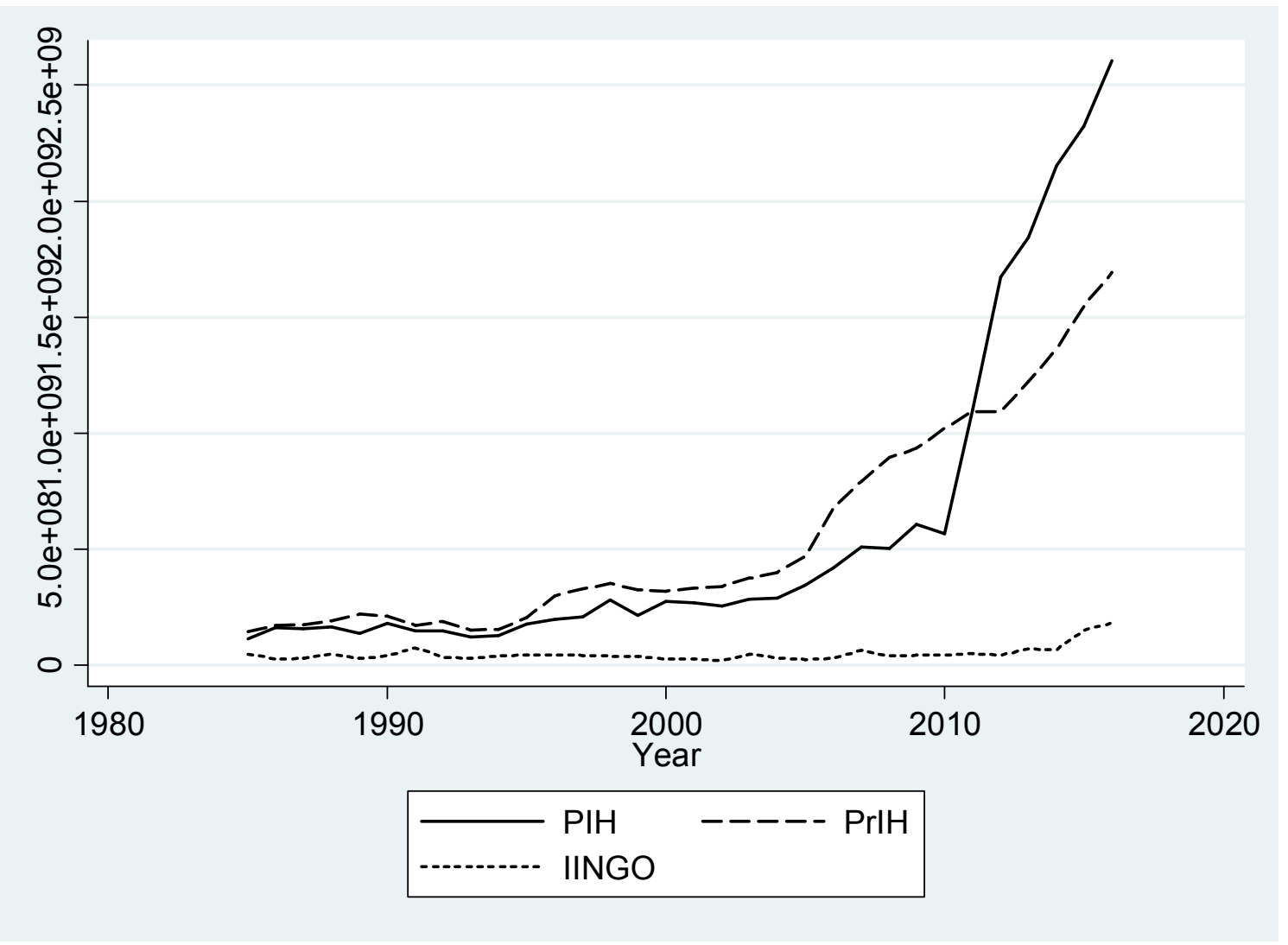

Figure 2. Growth Plots for Independent Variables.

The variables included are public investment in health $(\mathrm{PIH})$, private investment in health $(\mathrm{PrIH})$ and investment in health by INGOs (IINGO). The plots indicate that both private and public investments in health had an upward trend. Investment in health by INGOs was very minimal compared to the investments by private and by public entities. Moreover, the plots indicate that private investment in health surpassed public investment in health from 1985 to 2011. From 2011 to 2016, annual public investment in health was more than annual investment in health by private entities.

\subsection{Diagnostic Tests}

The study conducted post-analysis diagnostics that included testing for heteroscedasticity, serial correlation and normality of residuals. In testing the presence or lack thereof of heteroscedasticity, the Breusch-Pagan Cook Weisberg's was used. The test's null hypothesis is that there is homoscedasticity. The test implies that when $p$ value is more than 0.05 , that is evidence of homoscedasticity, but there is evidence of heteroscedasticity when the $p$ value is less than 0.05 . Testing for homoscedasticity was performed after running a regression model with GDP as the dependent variable while public investment in health, private investment in health and investment in health by INGOs as the dependent variables. Results presented in Table 1 show that the $\mathrm{p}$ value of the test was above 0.05 ( $\mathrm{p}$ $=0.3928)$ and hence the null hypothesis of homoscedasticity could not be rejected. The conclusion was that there was no heteroscedasticity.

Table 1. Test of Heteroscedasticity.

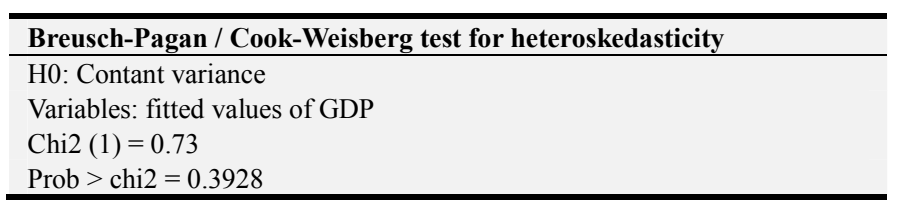

The Breusch Godfrey Lagrange multiplier test was used to test for serial correlation. This was performed after running the VECM model. The test results applied three lags to establish any serial correlation of higher order. The null hypothesis in this test is that there is no serial correlation. The null hypothesis is accepted when the $\mathrm{p}$ value is greater than 0.05 , when $\mathrm{p}$ value is less than 0.05 , this is a sign of serial correlation (See Table 2). The results indicate that there was no serial correlation for all the three lags used ( $p$ values $>0.05$ ).

Table 2. Test of Serial Correlation.

\begin{tabular}{llll}
\hline \multicolumn{4}{l}{ Breusch-Godfrey IM test for autocorrelation } \\
\hline Lags (p) & Chi2 & Df & Prob > Chi2 \\
\hline 1 & 000 & 1 & 0.9850 \\
2 & 2.695 & 2 & 0.2600 \\
3 & 3.754 & 3 & 0.2893 \\
H0 No serial correlation & & \\
\hline
\end{tabular}


The researcher also tested for normality of residuals to establish whether the residuals when the variables are regressed are normally distributed. This test was conducted by overlaying the errors of residuals over a normal distribution. The test was conducted after running the VECM model (See Figure 1). The results show that residuals did not vary significantly from a normal distribution therefore the residuals are normally distributed.

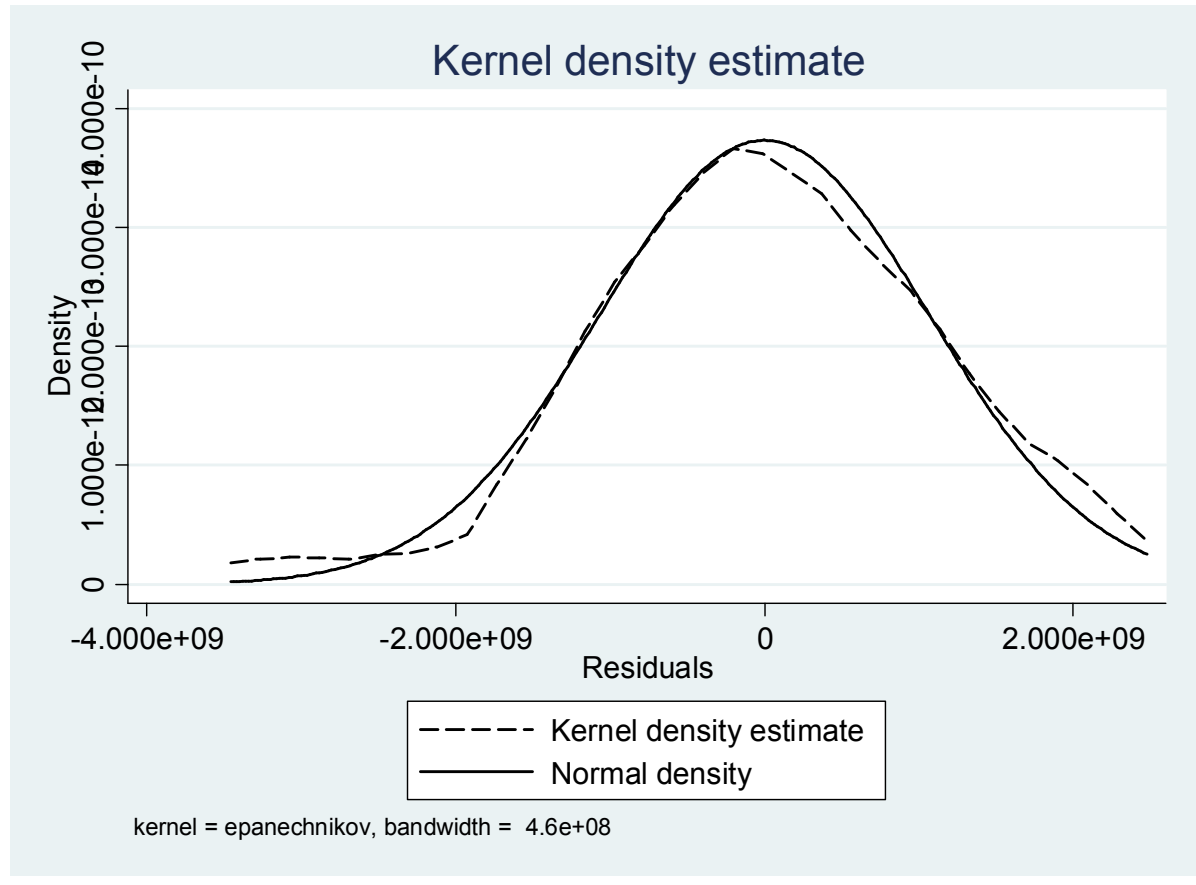

Figure 3. Test of Normality of Residuals.

\subsection{Selecting Number of Lags}

The study used time-series data from 1985 to 2016. After the diagnostic tests, time-series model fitting process was done. The VECM or VAR time-series analysis method were to be used. To assess which of the two models was appropriate for the data, the correct number of lags to be used needed to be assessed. This was examined using VAR and
VECM pre-estimation diagnostics command (See Table 3)where the Hannan and Quinn information criterion (HQIC), Lag length (LL), Akaike's Information Criterion (AIC), the Likelihood Ratio (LR) and the Final Prediction Error (FPE) were used. The study applied two lags as most of the lag selection criteria indicated two lags were appropriate.

Table 3. Selecting Number of Lags.

\begin{tabular}{|c|c|c|c|c|c|c|c|c|}
\hline \multicolumn{9}{|c|}{ Selection-order criteria } \\
\hline \multicolumn{6}{|c|}{ Sample: 1987-2016 } & \multicolumn{3}{|c|}{ Number of Observations $=\mathbf{3 0}$} \\
\hline Lag & $\mathbf{L L}$ & LR & df & $\mathbf{p}$ & FPE & AIC & HQIC & SBIC \\
\hline 0 & -2756.48 & & & & $9.9 \mathrm{e}+74$ & 184.032 & 184.092 & 184.219 \\
\hline 1 & -2648.65 & 215.67 & 16 & 0.000 & $2.2 \mathrm{e}+72$ & 177.91 & 178.209 & $178.844^{*}$ \\
\hline 2 & -2628.39 & $40.519 *$ & 16 & 0.001 & $1.8 \mathrm{e}+72 *$ & $177.626^{*}$ & $178.164 *$ & 179.307 \\
\hline
\end{tabular}

\subsection{Unit Root Tests}

The Augmented Dickey Fuller (ADF) test was used to test if the variables in the study had unit roots or were stationary.

Table 4. Unit Root Test for Study variables.

\begin{tabular}{lllll}
\hline Variable & $\begin{array}{l}\text { Test } \\
\text { statistic }\end{array}$ & $\begin{array}{l}\mathbf{1 \%} \text { critical } \\
\text { value }\end{array}$ & $\begin{array}{l}\mathbf{5 \%} \text { critical } \\
\text { value }\end{array}$ & $\begin{array}{l}\mathbf{1 0 \%} \text { critical } \\
\text { value }\end{array}$ \\
\hline GDP & 4.647 & -3.079 & -2.983 & -2.623 \\
PIH & 3.843 & -3.079 & -2.983 & -2.623 \\
PrIH & 4.614 & -3.079 & -2.983 & -2.623 \\
IINGO & 4.380 & -3.079 & -2.983 & -2.623 \\
\hline
\end{tabular}

When conducting time-series analysis, it is important for the variables to be stationary or have no unit rootsbecause regression using non-stationary variables can produce invalid estimates (See Table 4). The study applied the 5\% critical value to establish stationarity of the variables. The study results indicated that all the variables were stationary because all the test statistics for all variables were greater than the $5 \%$ critical value. This indicated that the regression of the variables would provide reliable estimates.

\subsection{Cointegration Tests}

Test of cointegration was applied to assess which of the two models (VECM or VAR) appropriate for the data. Cointegration in time series modelinfers that the variables in the model have a long-term relationship demonstrating that 
one variable can be applied to describe another variable in the long term (See Table 5). The study findings specify that the hypothesis of no cointegration was not accepted as the trace statistic of zero cointegration (79.5981) was higher that the critical value at 5\% (47.21). The findings show that there was at least one cointegration equation (indicated by the star on 8.7305 trace statistic). These study results indicate that VECM was the appropriate model to use for the data.

Table 5. Johansen Test for Cointegration.

\begin{tabular}{|c|c|c|c|c|c|}
\hline \multicolumn{5}{|c|}{ Trend: constant } & \multirow{2}{*}{$\begin{array}{l}\text { Number of obs - } 31 \\
\text { Lags - } 1 \\
\end{array}$} \\
\hline Sampl & & & & & \\
\hline \multicolumn{6}{|c|}{$5 \%$} \\
\hline Maxin & & & & trace & critical \\
\hline Rank & parms & $\mathbf{L L}$ & eigenvalue & statistic & value \\
\hline 0 & 4 & -2775.4171 & & 79.5981 & 47.21 \\
\hline 1 & 11 & -2751.0344 & 0.77877 & 32.8329 & 29.68 \\
\hline 2 & 16 & -2739.9832 & 0.54045 & $8.7305^{*}$ & 15.41 \\
\hline 3 & 19 & -2735.7302 & 0.23996 & 0.2244 & 3.76 \\
\hline 4 & 20 & -2735.618 & 0.00721 & & \\
\hline
\end{tabular}

\subsection{Vector Error Correction Model (VECM)}

The error correction model was run with GDP being the dependent variable while Public investment in health, private investment in health and investment in health by INGOs as the independent variables. The study applied two lags in the model as per previous results on lag order selection criteria. The VECM model was then developed with results as presented in Table 4.6. The study results indicated that there was one cointegration equation with a negative error correction term $(\beta$ $=-.1647)$. However, this error correction term was not significant at $5 \%$ level $(\mathrm{z}=-1.57 ; \mathrm{p}>0.05)$. These results indicate that when the error term in the cointegration equation is positive, GDP in Kenya falls, but not significantly. The results (See Table 6) suggest that lagged public investment in health had a positive short-term effect on GDP $(\beta=0.1149$; $p<$ $0.05)$. Private investment in health had a significant positive effect on GDP $(\beta=0.2407 ; p<0.05)$. The results however indicated that investment in health by INGOs did not have a significant effect on GDP $(\beta=0.3232 ; p>0.05)$. The resultant time series equation was of the form;

$$
\mathrm{GDP}_{\mathrm{t}}=1.01 \mathrm{e} 9+0.1149 \mathrm{PIH}_{\mathrm{t}}+0.2407 \mathrm{PrIH}_{\mathrm{t}}+32.32 \mathrm{IINGO}_{\mathrm{t}}
$$

However, investment in healthcare by INGOs could be dropped from the model as it had no significant effect on GDP (See Figure 2 and Table 6). The VECM model results were used to test the hypotheses of the study. Study findings alluded that public investment in health had a positive and significant effect on GDP $(\beta=0.1149 ; \mathrm{p}<0.05)$. This evidence led to the rejection of the first hypothesis and the alternative hypothesis was therefore accepted. The conclusion of the study was therefore that public investments in health have significant positive effect on the development of the economy in Kenya. These results support the findings of Piabuo and Tieguhong (2017) and Kareem et al. (2017) which argue that public investment in health had a positive and significant effect on economic growth of two sets of African countries that were incorporated in the study.

The findings suggest that private investment in health had a significant positive effect on GDP $(\beta=0.2407$; $p<0.05)$. The null hypothesis was therefore rejected. These results support the Solow-Swan exogenous growth model (1956) which explains long-run economic growth as a function of labour, capital accumulation and population growth, and growths in productivity which is because of technological progress.

Table 6. Vector Error Correction Model.

\begin{tabular}{|c|c|c|c|c|c|c|}
\hline \multicolumn{7}{|c|}{ Vector error-correction model } \\
\hline \multirow{2}{*}{\multicolumn{4}{|c|}{ Sample $1987-2016$}} & \multicolumn{3}{|c|}{ No. Of obs- 30} \\
\hline & & & & \multicolumn{3}{|c|}{ AIC- 178.0633 } \\
\hline Log likelihood - & -2643.949 & \multicolumn{5}{|c|}{ HQIC- 178.4667 } \\
\hline Det (sigma_ml) & $4.17 \mathrm{e}+71$ & \multicolumn{5}{|c|}{ SBIC- 179.3244 } \\
\hline Equation & Farma & RMSE & R-Sq. & Chi2 & \multicolumn{2}{|l|}{ p>chi2 } \\
\hline D_GDP & 6 & $1.7 \mathrm{e}+09$ & 0.8018 & 97.09663 & \multicolumn{2}{|l|}{0.0000} \\
\hline D_PIH & 6 & $1.3 \mathrm{e}+10$ & 0.5620 & 30.79521 & \multicolumn{2}{|l|}{0.0000} \\
\hline D_PrIH & 6 & $4.4 \mathrm{e}+09$ & 0.7666 & 78.83304 & \multicolumn{2}{|l|}{0.0000} \\
\hline D_IINGO & 6 & $2.0 \mathrm{e}+07$ & 0.3761 & 14.46699 & \multicolumn{2}{|l|}{0.0248} \\
\hline & Coef. & Std. Err. & $\mathrm{z}$ & $\mathrm{p}>/ \mathrm{z} /$ & \multicolumn{2}{|c|}{ [95\% conf. Interval] } \\
\hline \multicolumn{7}{|l|}{$\begin{array}{c}\text { D_GDP } \\
\text { _Cel }\end{array}$} \\
\hline L1-GDP & -.1646873 & .1052026 & -1.57 & 0.117 & -.3708806 & .0415061 \\
\hline LD-PIH & -.052435 & .2204652 & -0.24 & 0.808 & -.4855388 & .3786688 \\
\hline LD-PrIH & .1149255 & .0307702 & 3.05 & 0.000 & -.054617 & .175234 \\
\hline LD. IINGO & .240697 & .0788804 & 3.05 & 0.002 & .0860943 & .3952997 \\
\hline LD & 32.32409 & 16.83339 & 1.92 & 0.055 & -.6687508 & 65.31693 \\
\hline cons & $1.01 \mathrm{e}+09$ & $4.84 \mathrm{e}+08$ & 2.08 & 0.037 & $591 \mathrm{e}+07$ & $1.96 \mathrm{e}+09$ \\
\hline
\end{tabular}


The model recognizes human capital as a significant tool for continued endogenous growth.

Table 7. Normalized Cointegration Model.

\begin{tabular}{|c|c|c|c|c|c|c|}
\hline Equation & \multicolumn{2}{|l|}{ Parms } & \multicolumn{2}{|l|}{ chi2 } & \multicolumn{2}{|l|}{ p>chi2 } \\
\hline cel & 3 & & 7285.157 & & 0.0000 & \\
\hline \multicolumn{7}{|c|}{ Identification: beta is exactly identified } \\
\hline \multicolumn{7}{|c|}{ Johansen normalization restriction imposed } \\
\hline beta & Coef. & Std. Err. & Z & $\mathrm{p}>/ \mathrm{z} /$ & {$[95 \%$ conf. } & \\
\hline _cel GDP & 1 & - & - & - & - & \\
\hline $\mathrm{PIH}$ & -.0128386 & .0047886 & -2.68 & 0.007 & -0.222241 & -.0034532 \\
\hline PrIH & -.3684913 & .0056214 & -65.55 & 0.000 & -.3795091 & -.3574735 \\
\hline IINGO & -15.16797 & 11.96497 & -1.27 & 0.205 & -38.61888 & 8.282943 \\
\hline CONS & $-3.28 \mathrm{e}+08$ & - & - & - & - & - \\
\hline
\end{tabular}

The findings also support the conclusion reached by Aboubacar and Xu (2017) that private health investment had a significant effect on the economic growth of the countries in the region. Study results indicate that investment in health by INGOs did not have a significant effect on GDP $(\beta=$ $0.3232 ; \mathrm{p}>0.05)$. The null hypothesis was therefore accepted. These findings contradict those of Myanmar by the Global Health Fund (2016) which suggests that international organizations' assistance in the health sector had enabled the country to reach grand convergence and pro-poor universal health coverage thus improving its human capital and productivity.

The study developed the normalized cointegration equation (See Table 7). The results suggest that in the long term, the three independent variables included in the study (public investment in healthcare, private investment in healthcare and investment in healthcare by INGOs) had an effect on GDP (chi square $=7285.157 ; p<0.05$ ). The results also indicate that public investment in health $(\beta=-0.0128 ; \mathrm{p}$ $<0.05)$ and private investment in health $(\beta=-0.3685$; $p<$ 0.05 ) had a significant long term causal effect on GDP. However, investment in health by INGOs did not have a significant long term causal effect on GDP $(\beta=-15.1680 ; p>$ $0.05)$.

\subsection{Effect of Shocks in Investment in Health on GDP}

The study used the impulse response functions (IRF) to assess the effect of structural shocks in investment in health on GDP. Moreover, IRFs were used to assess whether responses to the shocks died out with time. Figure 4 Presents the IRFs for impulses of public investments in health, private investment in health and investment in health by IINGOs on GDP.

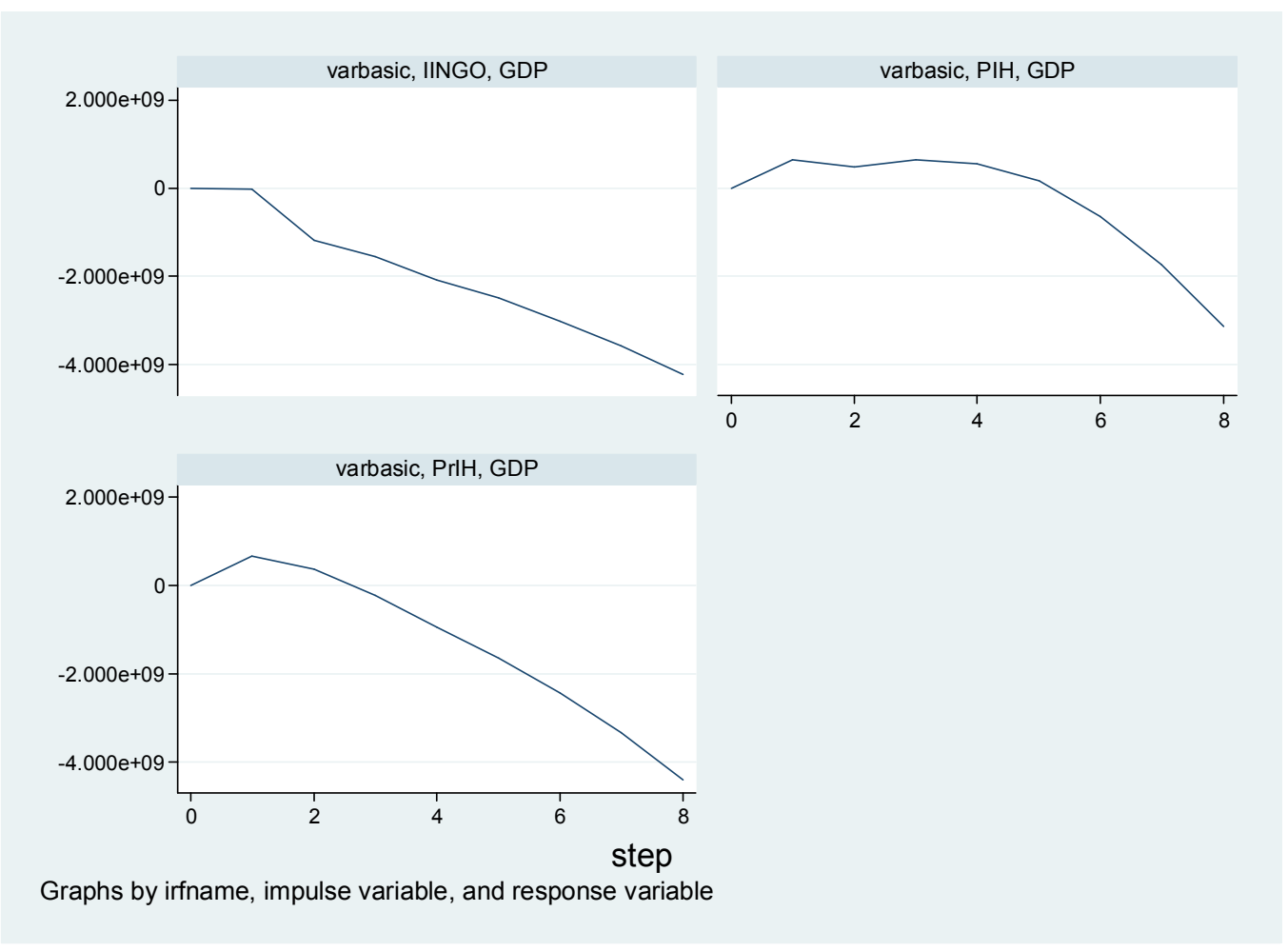

Figure 4. Effect of Shocks in Investment in Health on GDP. 
The results in Figure 4 indicate that impulse shocks on investments in health by IINGOs may is likely not to have any effect on GDP in the first year but is likely to cause GDP to decrease after the first year. This effect of the shock may not die out over time and hence it could be considered permanent. Further, shocks on public investment in health are likely to cause GDP to increase in the first five years while they may make GDP to decrease from year five. This might be permanent as it does not seem to die out. Similarly, shocks on private investment in health may cause a rise in GDP in the first two years but the GDP may fall after year three. This effect may also be permanent as it does not revert to its mean over time.

\section{Conclusion}

The study concludes that public investment in health have a significant positive effect on economic development in Kenya. This may due to the increased productivity of the population due to improvement in human capital which in turn leads to improved productivity. Increased investment by government in the health sector can enhance economic development by increased productivity in other sectors that provide services and products to the health sector. Secondly, the study concludes that Private Investment in the health sector have a positive and significant effect on economic development of Kenya. Avenues through which private investment can significantly improve economic development includes in enhancing human capacity for increased productivity and increased productivity in related sectors. Lastly, the study concludes that investment in the health sector by international non-governmental organizations does not have a significant effect on economic development of Kenya. The reason behind this can be due to the contribution of INGOs being minimal compared to the contribution made by the government and the private sector in the health care sector.

\section{Recommendations}

The study makes the following recommendations. First, the government has increased its investment in the health sector which is laudable. The investment by government in the health sector surpassed the investment by the private sector in 2011 and it has been increasing since. This indicates focus by the government to enhance health of its citizens. Secondly, the study recommends that the government should encourage private entities to increase their investment in the health sector in the country. From 1985 to 2011, private investment in health sector surpassed government spending. However, as government significantly increased its investment in 2011 onwards, this was not matched by a similar increase by the private sector. Policy framework should be designed that encourage the private sector to increase its investment in the health sector. Lastly, the ministry of health and other government stakeholders should partner with private sectors health care providers to come up with a framework to ensure that INGOs increase their funding to financial deficit health sector units or activities. Moreover, the INGOs and government should have a governance framework to ensure that financing by INGOs is effectively utilized.

\section{References}

[1] Aboubacar, B. \& Xu, D. (2017). The Impact of Health Expenditure on the Economic Growth in Sub-Saharan Africa. Theoretical Economics Letters, 7, 615-622.

[2] Bloom, D. E. \& Canning, D. (2008). Population Health and Economic Growth. The International Bank for Reconstruction and Development / The World Bank On behalf of the Commission on Growth and Development. Washington DC.

[3] Creswell, J. (2013). Research Design; Qualitative and Quantitative and Mixed Methods Approaches (3rd ed.). London: Sage.

[4] Eneji, M. A., Juliana, D. V., \& Onabe, B. J. (2013). Health care expenditure, health status and national productivity in Nigeria (1999-2012). Journal of Economic and International Finance, 5(7), $258-271$.

[5] Gallup, J. L. \& Sachs, J. D. (2001). The Economic Burden of Malaria. American Journal of Tropical Medicine and Hygiene, 64 (1), 85-96.

[6] Global Health Fund (2016). investing in health in Myanmar: How can the country reach grand convergence and pro-poor universal health coverage? Naypyidaw: Global Health Fund.

[7] Grossman, M. (2014). On the concept of health capital and the demand for health. Journal of Political Economy, 120, 223255 .

[8] Hsiao, W. \& Heller, P. (2007). What should macroeconomists know about health care policy?'IMF Working Paper, no WP/07/13, International Monetary Fund, Washington DC.

[9] Kareem, R. O., Ademoyewa, G., Fagbohun, O. L. \& Arije, B. (2017). Impact of Federal Government's Healthcare Expenditure on Economic Growth of Nigeria. Journal of Research in Business, Economics and Management, 8(1), 1329 -1343.

[10] Kirigia, J. M., Oluwole, D., Mwabu, G. M., Gatwiri, D. \& Kainhu, L. H. (2006). Effects of maternal mortality on gross domestic product (GDP) in the WHO African region. Africa Journal of Health Science Vol 13, 86-95.

[11] Martin, G., Grant, A., \& D’Agostino, M. (2012). Global health funding and economic development. Globalization and Health, 8(8), $720-731$.

[12] Mehmood, B., Syed, H., Raza, S. H., \& Mureed, S. (2014). Health Expenditure, Literacy and Economic Growth: PMG Evidence from Asian Countries. Euro-Asian Journal of Economics and Finance, 2(4), 408-417.

[13] Musgrave, R. A. (1969). Fiscal Systems. New Haven and London: Yale University Press.

[14] Piabuo, S. M., \& Tieguhong, J. C. (2017). Health expenditure and economic growth - a review of the literature and an analysis between the economic community for central African states (CEMAC) and selected African countries. Health Economic review, 7: 23. Doi: 10.1186/s13561-017-0159-1. 
[15] Robson, C. (2012). Real world research: A resource for social scientists and practitioner-researchers (6th ed.). Oxford: Blackwell.

[16] Sammut, A. (2013). Assessing the Relationship between Health and Economic Growth: Malta's Case. Master of Economics thesis, University of Malta.

[17] Solow, R. M. (1956). A contribution to the theory of economic growth. Quarterly Journal of Economics, 70 (1), $65-94$.

[18] UNDP(2016). MDG status report for Kenya. Retrieved from: http://www.ke.undp.org/content/kenya/en/home/library/mdg/2 014-mdg-status-report-for-kenya.html.

[19] Wagner, A. (1883). Three Extracts on Public Finance in R. A. Musgrave and A. T. Peacock (eds) (1958). Classics in the Theory of Public Finance. London: Macmillan.

[20] Wang, K. M. (2013). Health care expenditure and economic growth: quantile panel-type analysis, Economic Modelling, 28, 1536-1549.

[21] World Health Organisation (2015). Status of health in Kenya. Geneva: WHO. 